
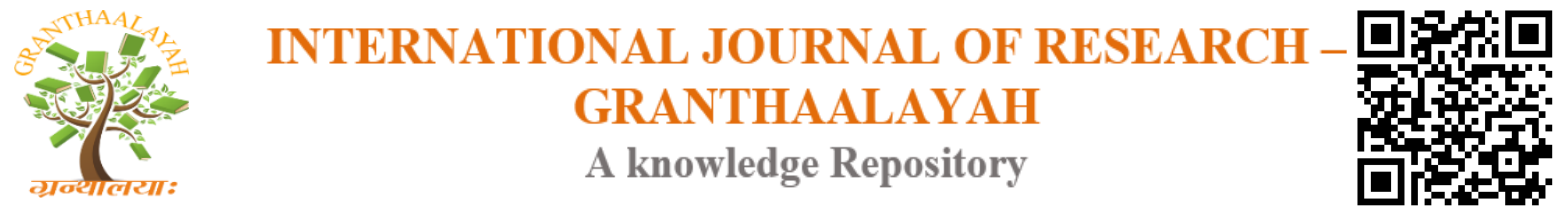

Science

\title{
THE PARAMAGNETISM AND SHOCK WAVES EFFECTS OF INTACT OR RUPTURED OXYGEN BUBBLES CAUSING PROKARYOTIC AND EUKARYOTIC CELLS DEFORMATIONS: SUPPORTING THE HYPOTHESIS OF CELL RESPIRATION AS ADDITIONAL FACTOR IN CANCER ORIGING
}

\author{
Abraham A. Embi Bs MBA *1 \\ ${ }^{* 1} 13442$ SW 102 Lane, Miami, Florida USA, 33186
}

\begin{abstract}
Background:

Demonstrated is energy released by rupturing paramagnetic oxygen bubbles from $\mathrm{H}_{2} \mathrm{O}_{2}$ decomposition causing human cells structural deformations. The aim is to add evidentiary support to a previously published biophysical cancer origin hypothesis.

The Prokaryotic Cells: In previous research, lithotripsy shock waves rupturing air bubbles were demonstrated causing Red Blood Cells (RBCs) deformations. Recently, experiments using a technique allowing for the demonstration of temporary in vivo preservation of prokaryotic RBCs properties in in vitro blood smears was introduced. Rupturing of oxygen bubbles documented in causing RBCs deformations.

The Eukaryotic Cells: Previous papers also showed cell deformations caused by imploding oxygen bubbles.

Methods:

The Prokaryotic Cells Experiments: In this report, catalase powder was placed directly on wet blood smears. This maneuver triggered an immediate Reactive Oxygen Species (ROS) decomposing the intrinsic $\mathrm{H}_{2} \mathrm{O}_{2}$ molecules in blood tissue.

The Eukaryotic Cells Experiments: Human saliva and scrapped cheek cells were on a glass slide, catalase particles sprinkled and the preparation sandwiched by a second slide. All experiments were monitored and recorded by a video microscope (Celestron Model \# 44348) and stored in an Apple MacBook Pro photo application for viewing and evaluation.

Results:

In Prokaryotic Cells: Paramagnetism (attraction) from oxygen bubbles, as well as bursts of energy from its decomposition caused deformations of RBCs. The diamagnetic (graphite) and paramagnetic (iron) material also showing to induce cells deformations.

In Eukaryotic Cells: Paramagnetism (attraction) from oxygen bubbles, as well as bursts of energy from its rupture caused deformations of nucleated cells. Observed were the darkening of endoplasmic reticulum and changes in the internal structures, such as nucleus, Cells architectural external shapes deformations observed.
\end{abstract}




\section{Conclusions:}

This manuscript introduces two mechanisms inducing cells deformations, both having a common denominator, namely oxygen bubbles. Firstly, via a magnetic cross-talk between paramagnetic oxygen bubbles and diamagnetic human cells; and secondly, by the energy released from bubbles rupturing. The deformations were documented in both prokaryotic and eukaryotic cells. As cellular communication ensures biological processes, possible implications are the disruption of cellular communications with unforeseen consequences up to cancer genesis.

Keywords: Biomagnetism; Prokaryotic Cell Deformation; Eukaryotic Cell Deformation; $\mathrm{H}_{2} \mathrm{O}_{2}$ Breakdowns; Oxygen Paramagnetism; Cells Diamagnetism; Cancer Origin Hypothesis; Cell Respiration.

Cite This Article: Abraham A. Embi Bs MBA. (2019). “THE PARAMAGNETISM AND SHOCK WAVES EFFECTS OF INTACT OR RUPTURED OXYGEN BUBBLES CAUSING PROKARYOTIC AND EUKARYOTIC CELLS DEFORMATIONS: SUPPORTING THE HYPOTHESIS OF CELL RESPIRATION AS ADDITIONAL FACTOR IN CANCER ORIGING." International Journal of Research - Granthaalayah, 7(3), 177-188. https://doi.org/10.29121/granthaalayah.v7.i3.2019.958.

\section{Introduction}

\section{Background}

The main purpose of this manuscript is to demonstrate the role of the paramagnetic oxygen molecule effects on human cells structural deformations of both eukaryotic and prokaryotic types, these findings could confirm or support a previously published a biophysical cancer origin hypothesis. In a 2016 publication, the electromagnetic fields (EMFs) from the decomposition of $\mathrm{H}_{2} \mathrm{O}_{2}$ molecules by antioxidants during cell respiration was hypothesized as an additional factor in cancer origin (1). Prior research has shown that when air bubbles are ruptured, shock waves energy is released. This energy has been reported to cause cell deformations in both prokaryotic and Eukaryotic cells $(2,3)$

\section{A Brief History of Biomagnetism}

Biomagnetism has been described as an "Interdisciplinary Approach" (4). To date, the field of biomagnetism has been gradually developed and introduced in the medical literature. For example, the diamagnetic nature of blood was introduced in 1936 (5), the recording of biomagnetic emissions from the human body ie: Brain, Heart and Hair follicles were also published in the 1960s; with a recent increase in publications $(6,7,8,9,10,11)$. In this manuscript we could apply the Law of Universal Magnetism and state that energy would be emitted by the bursting of an oxygen bubble regardless of its size. (12).

Recently, a novel technique allowing for the demonstration of temporary in vivo preservation of prokaryotic cells such as red blood cells (RBCs) properties in in vitro blood smears allowing for the evaluation of the effects of both paramagnetic and diamagnetic fields on cells deformations (13). This technique for the purpose of this manuscript will be quoted by the acronym TIBS where $\mathrm{T}=$ Temporary, $\mathrm{I}=$ In Vivo, $\mathrm{B}=\mathrm{Blood}$ and $\mathrm{S}=\mathrm{Smear}$. 


\section{The Eukaryotic Cells}

In this manuscript another novel technique is also introduced that allows for the demonstration of effects by oxygen molecules on human cheek (eukaryotic) cells deformations.

\section{Methods}

\section{The Prokaryotic Cells Experiments}

As previously published, an optical microscopy technique now quoted as TIBS had been developed. In this report, catalase powder was placed directly on a TIBS preparation. This maneuver triggered an immediate Reactive Oxygen Species (ROS) decomposing the intrinsic $\mathrm{H}_{2} \mathrm{O}_{2}$ molecules in the RBCs. Additional particles with various magnetic properties were also placed TIBS, such as metal iron filings and the strong diamagnetic graphite powder. All experiments recorded in a video microscope and stored digitally for further analysis.

\section{The Eukaryotic Cells Experiments}

After numerous attempts, a successful experimental model is presented where human saliva and scrapped cheek cells were placed on a glass slide. Fine catalase particles were sprinkled and the preparation was sandwiched (SDW) by a second similar slide.

\section{Equipment}

All experiments were monitored and recorded by a video microscope (Celestron Model \# 44341) and stored in an Apple MacBook Pro photo application for viewing and evaluation.

\section{Results}

\section{In Prokaryotic Cells}

The fronting of opposing magnetic fields, such as the attraction of metal iron filings overriding the weaker diamagnetism or RBCs is shown to cause RBCs deformation. Paramagnetic and stronger diamagnetic materials are documented showing to induce RBCs live (ongoing) cells deformations (Figs 1,2,3,4,5,6 + video recordings). It should be noted that graphite powder was found to exhibit diamagnetism (repulsion) as well as paramagnetism (attraction) (14).

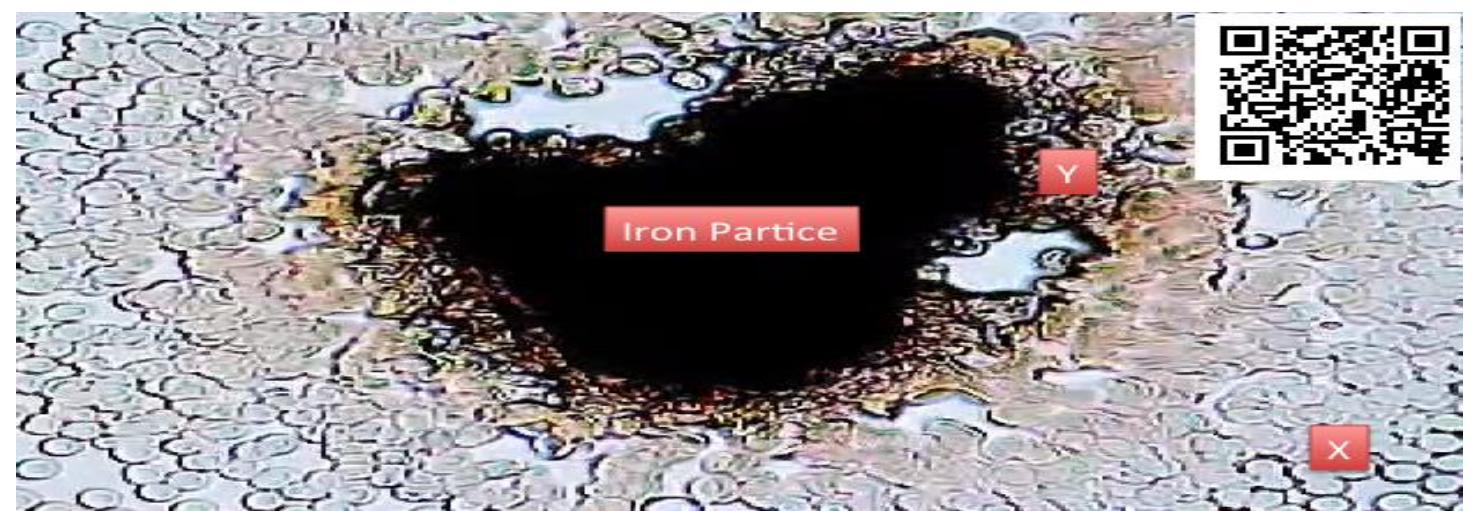

Figure 1: Microphotograph of video frame after moisture evaporation of a metal iron filing placed on blood smear during Temporary In vivo Blood Smear stage (TIBS). X= Blood smear. $\mathrm{Y}=$ Compressed RBCs by static magnetic attraction. For details visit https://youtu.be/5FOOZZ42nQ4 or scan QR Code on upper right image 
Image duplicated from: Abraham A. Embi Bs. (2019). "EXPANDING THE ROLE OF MAGNETIC FIELDS IN RED BLOOD CELLS DEFORMATIONS: DEMONSTRATION OF PARAMAGNETIC AND DIAMAGNETIC FIELDS." International Journal of Research Granthaalayah, 7(2), 214-220. https://doi.org/10.5281/zenodo.2587463.

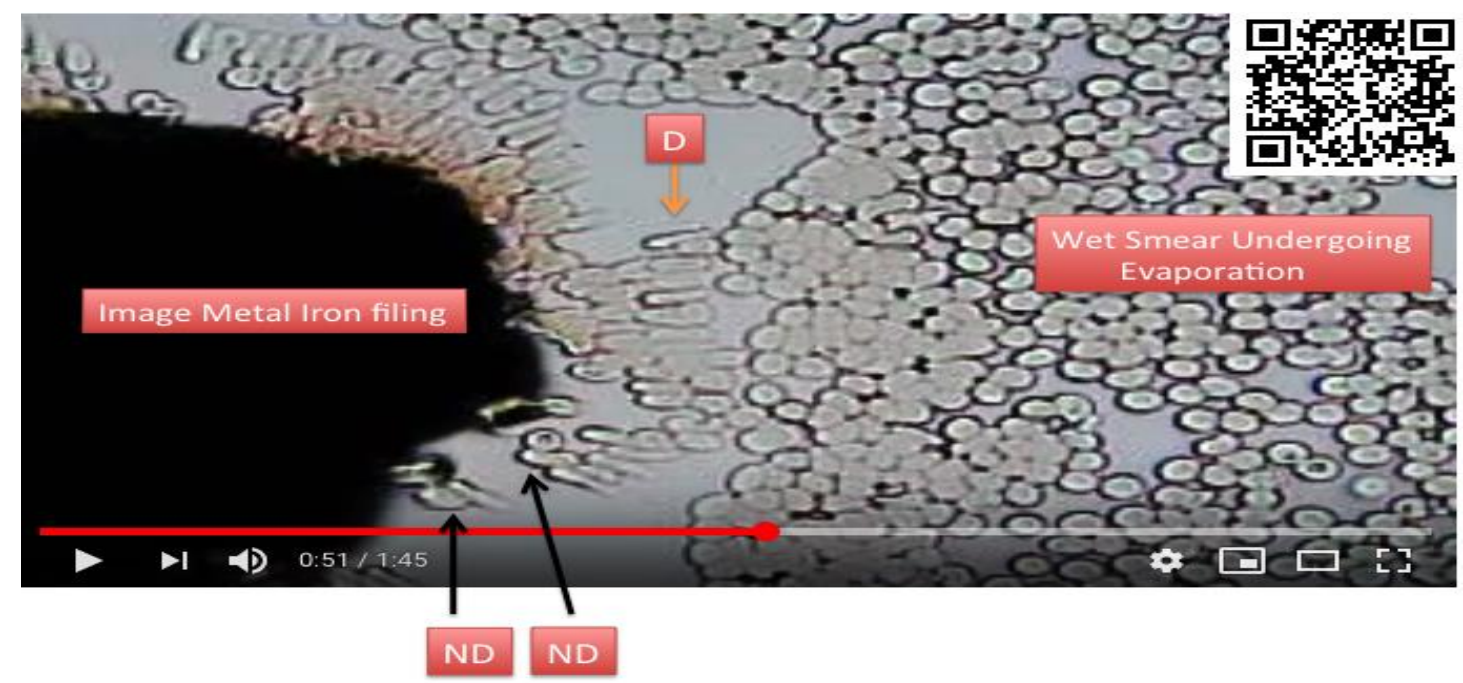

Figure 2: Video Frame at 0.51 ". Twenty three seconds later, Mechanism for genesis of RBCs shape deformations into teardrops on temporary vivo phase of blood in vitro smear (TBIS). $\mathrm{D}=$ Already Deformed RBCs. ND= RBCs to undergo metamorphosis. Please visit video recording at https://youtu.be/N1nDRm2-s5g or Scan QRcode image (top right corner).

Image duplicated from: Abraham A. Embi Bs. (2019). "EXPANDING THE ROLE OF MAGNETIC FIELDS IN RED BLOOD CELLS DEFORMATIONS: DEMONSTRATION OF PARAMAGNETIC AND DIAMAGNETIC FIELDS." International Journal of Research Granthaalayah, 7(2), 214-220. https://doi.org/10.5281/zenodo.2587463.

Relevant Note: To better appreciate the teardrop formation, suggest executing video replay repeatedly from frames 0.35 " forward and backguards to appreciate the transformations.

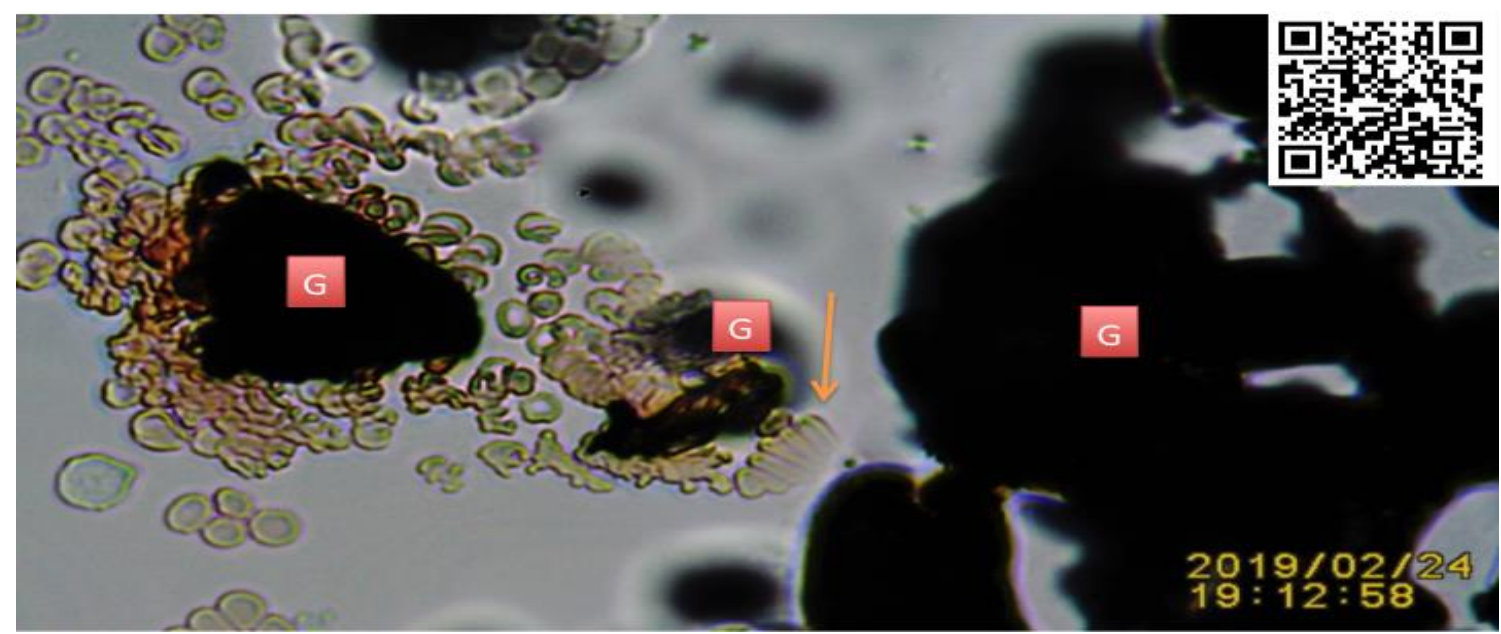

Figure 3: Microphotograph of RBCs in TIBS seen attracted and temporarily deformed as "teardrops" by the paramagnetic attraction of graphite powder. 
$\mathrm{G}=$ Graphite Powder. Orange Arrow= Deformed RBCs. For further details link to:

https://youtu.be/jvGJtinz2Sw or Scan QR Code on right corner or image.

Image duplicated from: Abraham A. Embi Bs. (2019). "EXPANDING THE ROLE OF MAGNETIC FIELDS IN RED BLOOD CELLS DEFORMATIONS: DEMONSTRATION OF PARAMAGNETIC AND DIAMAGNETIC FIELDS." International Journal of Research Granthaalayah, 7(2), 214-220. https://doi.org/10.5281/zenodo.2587463.

\section{The Catalase Powder Experiments}

\section{Effect of Paramagnetic $\mathrm{O}_{2}$ Molecules on RBCs Deformation}

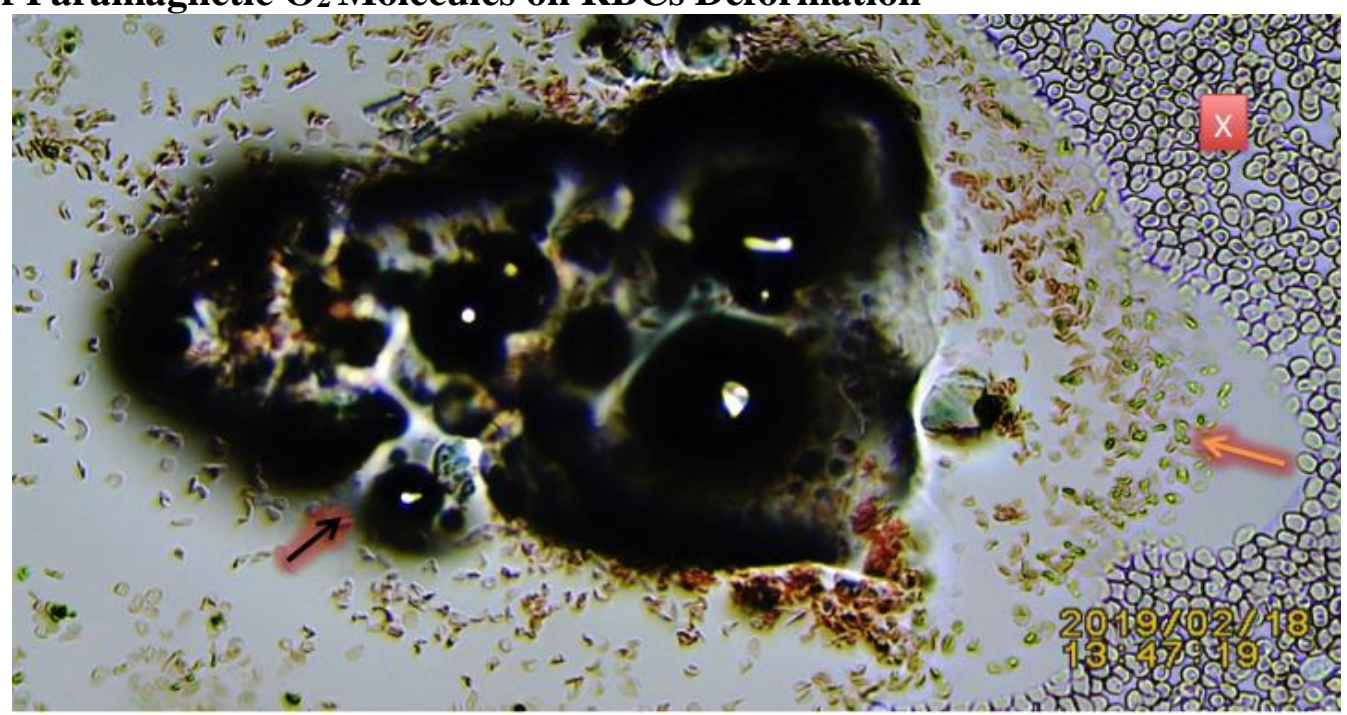

Figure 4: Microphotograph image of area where catalase is breaking down $\mathrm{RBCs} \mathrm{H}_{2} \mathrm{O}_{2}$ and releasing paramagnetic $\mathrm{O}_{2}$ molecules. Black Arrow= Pointing at catalase particle area. Orange Arrow $=$ Pointing at deformed RBCs field. $\mathrm{X}=$ Blood smear (TIBS).

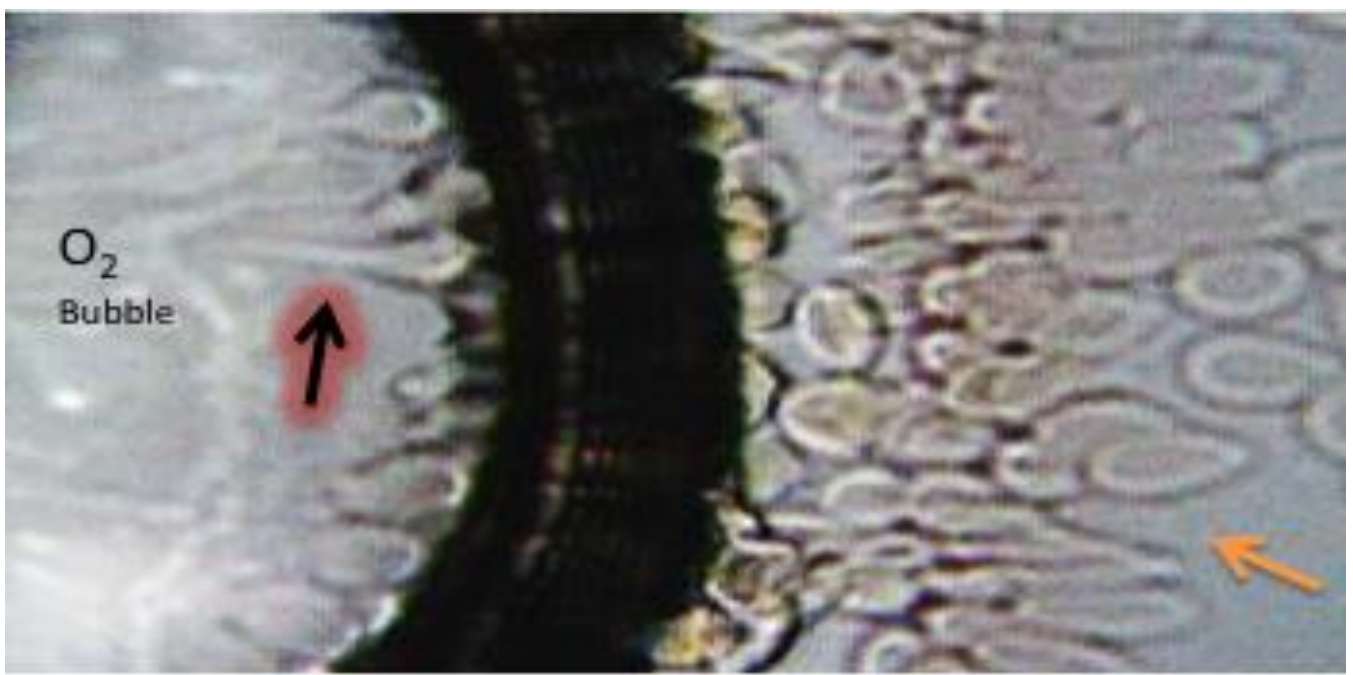

Figure 5: Partial view of oxygen bubble deforming live RBCs in a TIBS resulting from decomposition toxic $\mathrm{H}_{2} \mathrm{O}_{2}$ molecules in RBCs by an exogenous catalase particle,. Orange Arrow $=($ Right Lower Corner) Deformed RBCs. 
Highlighted Black Arrow $=$ The $\mathrm{O}_{2}$ bubble concave shape allows for the display of deformed cells pointing in the opposite direction.

For details click on link or scan QRcode below:
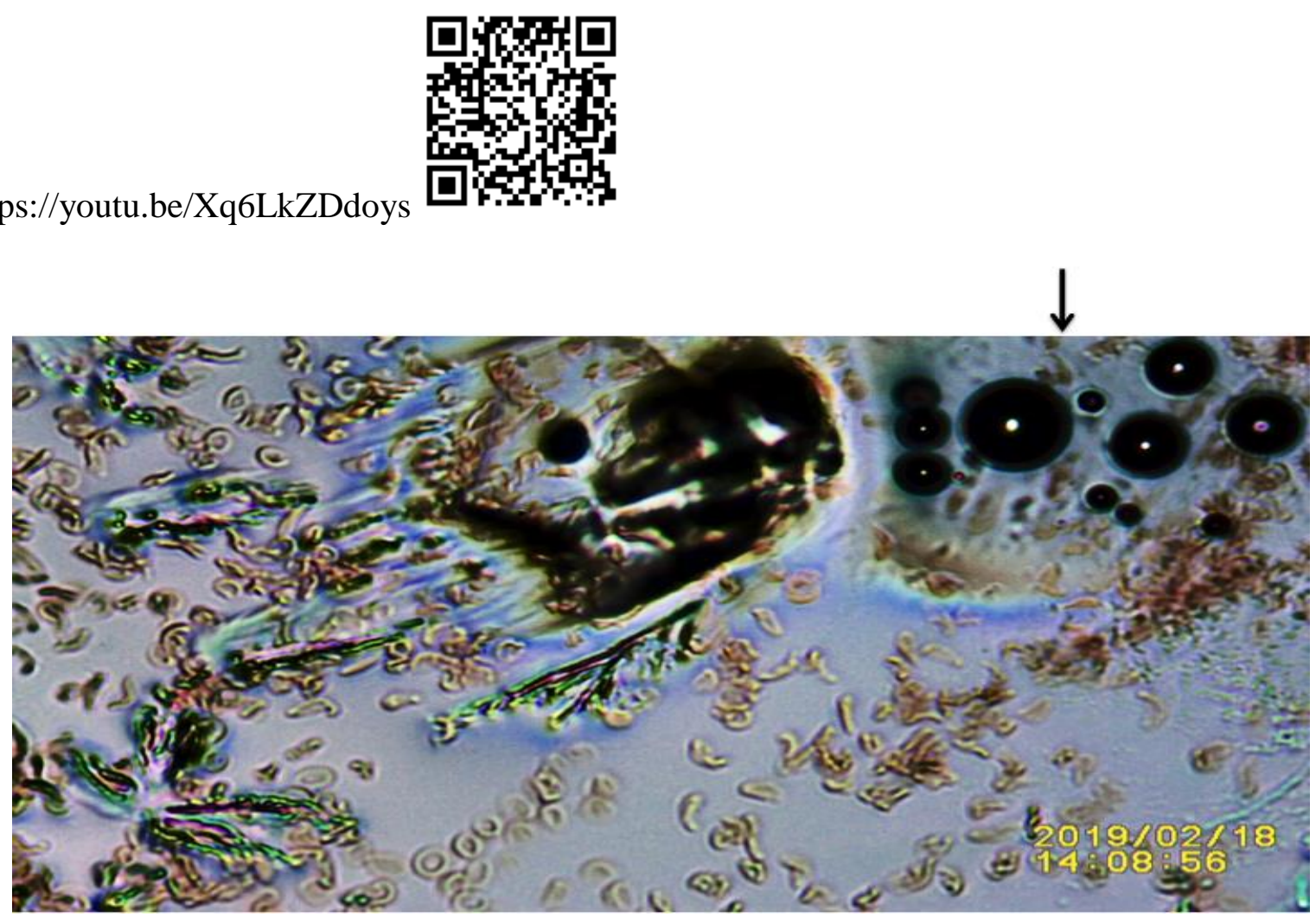

Figure 6: Depicting effect of powder catalase placed on TIBS. This slide appears to show material motion and cell deformation caused by released energy by bursting $\mathrm{O}_{2}$ bubbles. Black Arrow $=$ Pointing at ongoing $\mathrm{O}_{2}$ molecules formation triggered breakdowns. The deformed RBCs are not highlighted, since they can be appreciated in the debris field.

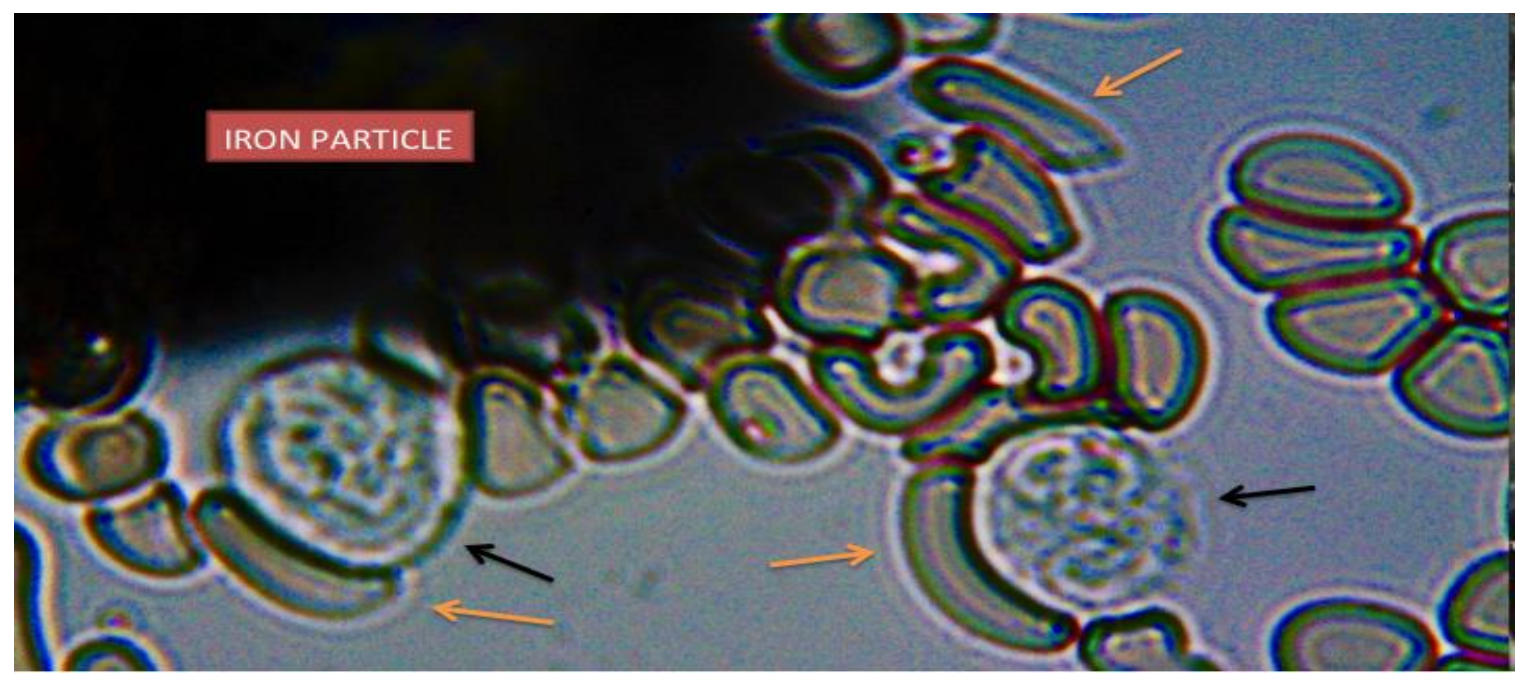

Figure 7: Metal iron filing paramagnetism fronting the diamagnetic blood tissue on TIBS showing: Orange Arrows $=$ RBCs cell deformations and Black Arrows= WBCs adhering to RBCs. 
Notice the lack of deformation caused by magnetism on the WBCs This is attributed to the absence of iron in the cell.

\section{In Eukaryotic Cells}

Nucleated cells were also seen moving and attracted by the oxygen bubble paramagnetism. Several observations were documented, such as darkening of endoplasmic reticulum and nucleus, suggested as result of oxygen transfer from aeration. Several types of cells deformations were also observed, the changes depending whether or not cells floating next to bubble. (Figs 7,8,9,10+ video recordings).

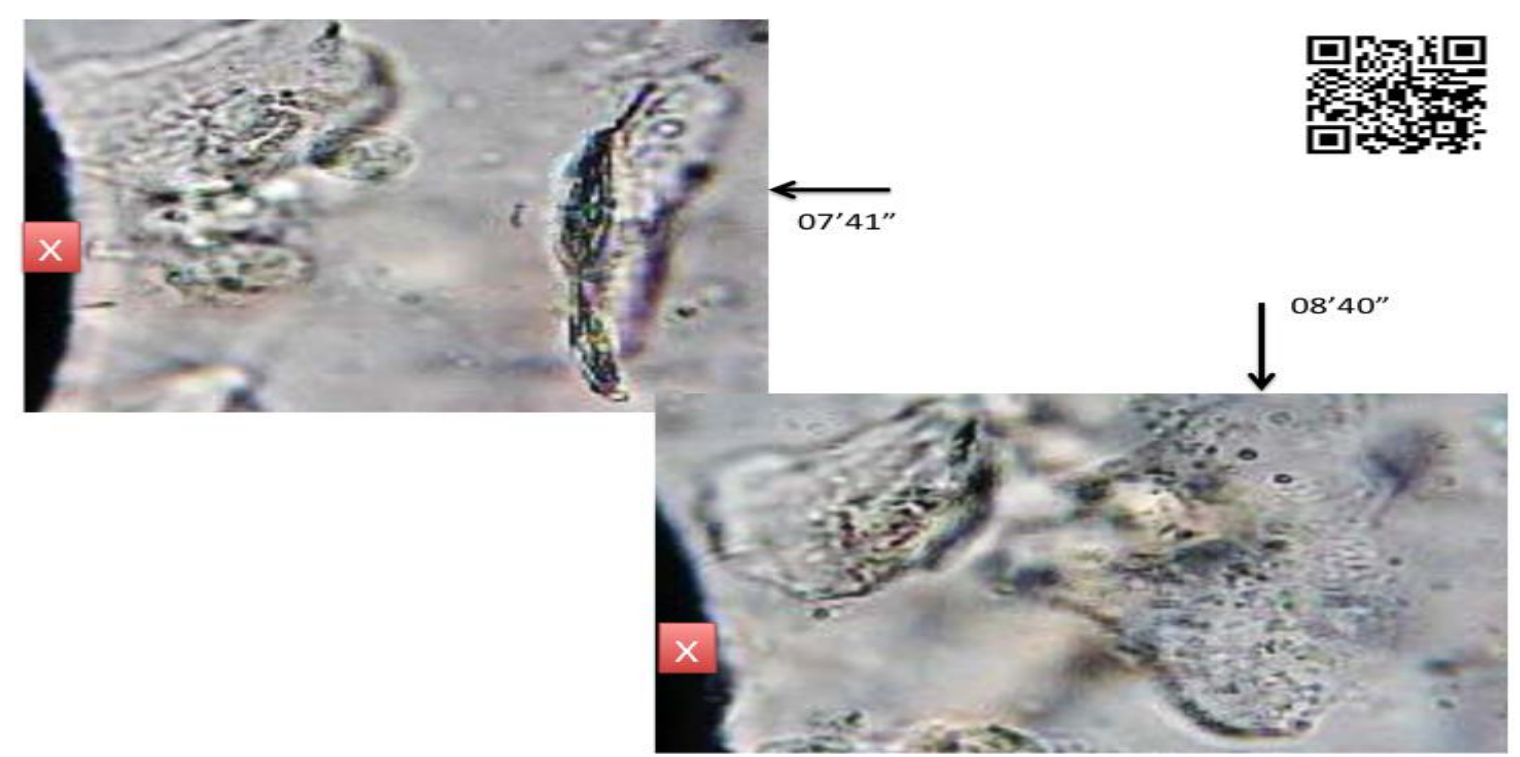

Figure 8: Demonstration of oxygen bubble paramagnetic fields deforming a cell by expansion, and another by compression. $\mathrm{X}=$ Oxygen bubble outer interface. This phenomenon was documented only when tandem cells were floating in same horizontal plane.

For additional details link to: https://youtu.be/yeVHLm4O6HA or scan QR Code in top right of picture. Suggested is to view from frame 07'41" to 08'40" for additional details.

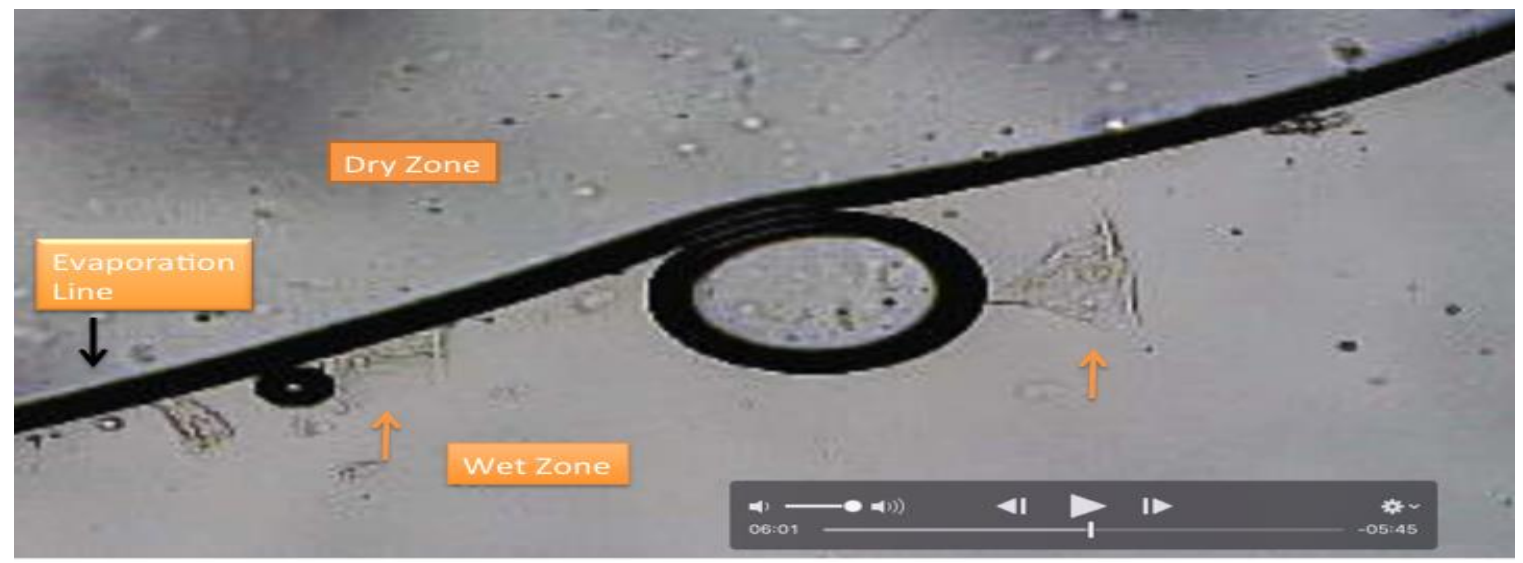

Figure 9: Demonstration of small and large oxygen bubble attraction to cheek cells (Orange Arrows). 


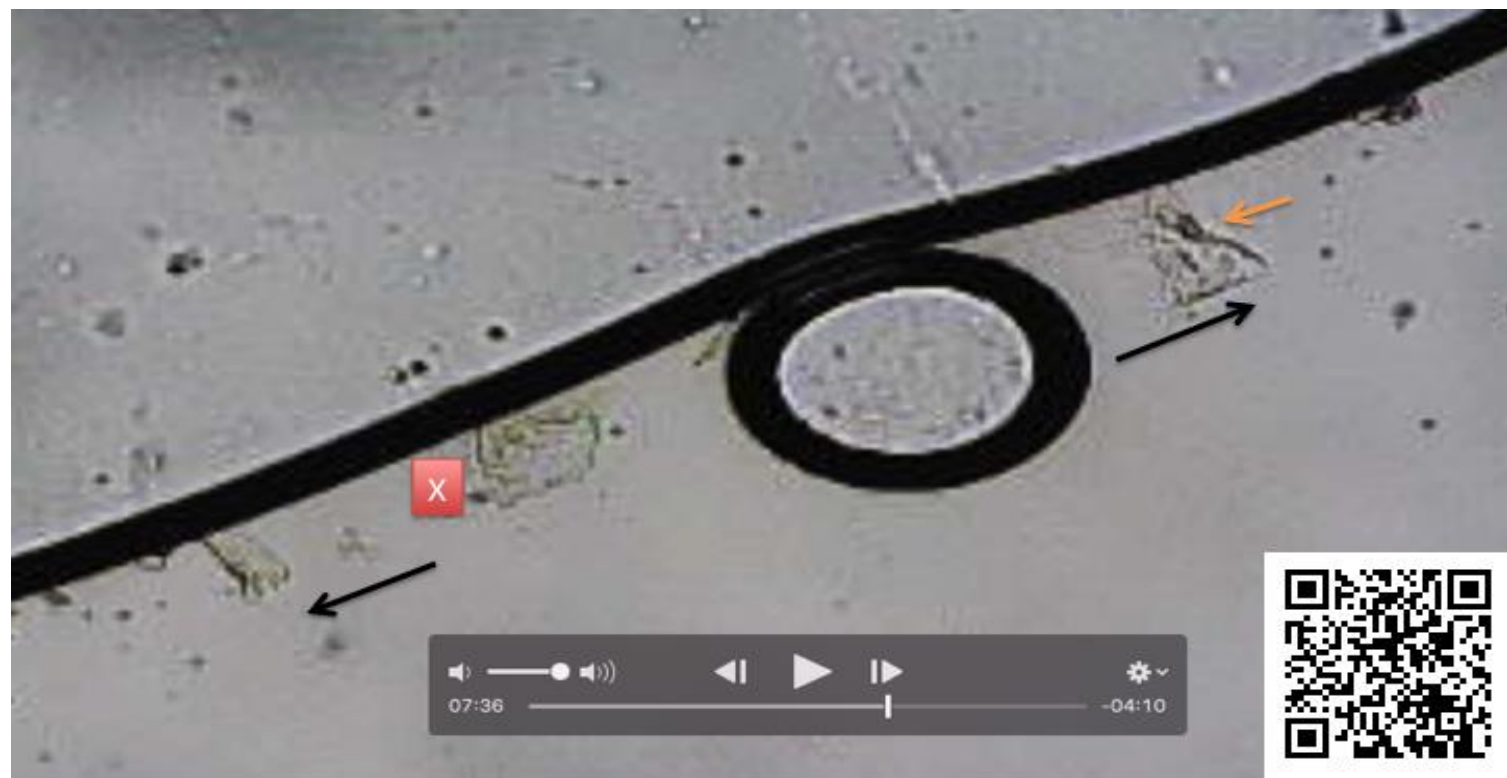

Figure 10: Small distant O2 bubble energy burst, dislodging cell from big bubble, causing structural changes. $\mathrm{X}=$ Site of former small bubble.

Orange Arrow: Pointing at dislodged cell from large bubble. Notice cell shape deformation attributed to small bubble energy.

Black Arrows: Bidirectional energy field. For further details visit link:

https://youtu.be/ue7B5oKUfmw

or Scan QR Code on bottom right of image.

Suggested is to scan video from 07'02" to 08'13" to appreciate the Oxygen Bubbles bursting effect on cells deformations,

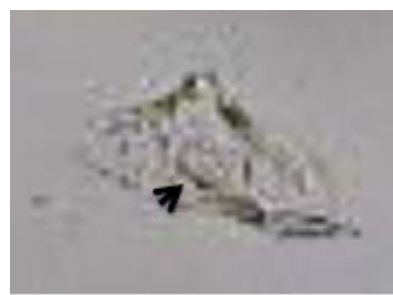

Control

C

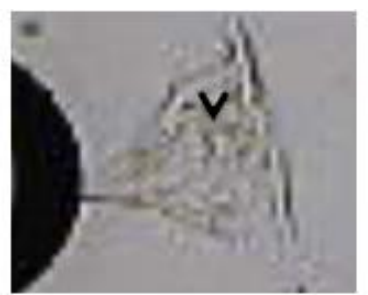

Paramagnetic Attraction of Large Oxygen Bubble

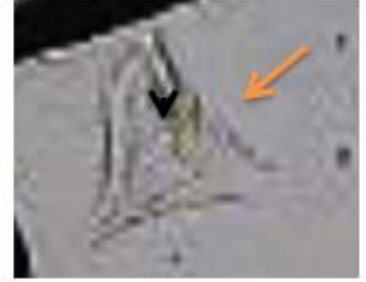

Small Bubble Burst Causing Deformation

S

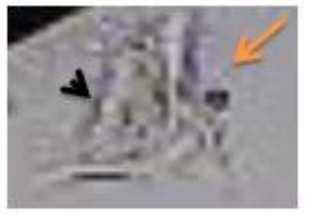

Large Bubble Burst Causing Further Deformation

L

Figure 11: Examples of cell deformation caused by rupture of two unequal oxygen bubbles. Panel showing selected copy and paste amplified images from video recording (shown in Figures 8,9,11 above). All four images displayed with same magnification. Orange Arrows = Cell deformation. $\mathrm{C}=$ Control cheek cell shape.

$\mathrm{P}=$ Large bubble paramagnetic attraction deformation $\mathrm{S}=$ Small bubble bursting deformation effect $\mathrm{L}=$ Larger bubble bursting deformation effect. 
Black Arrow Heads= Pointing at nucleus changes due to paramagnetism, as well as bubble bursting energy.

Additional Demonstration of Paramagnetism Attracting Cells and Debris Attracted by Oxygen Bubbles

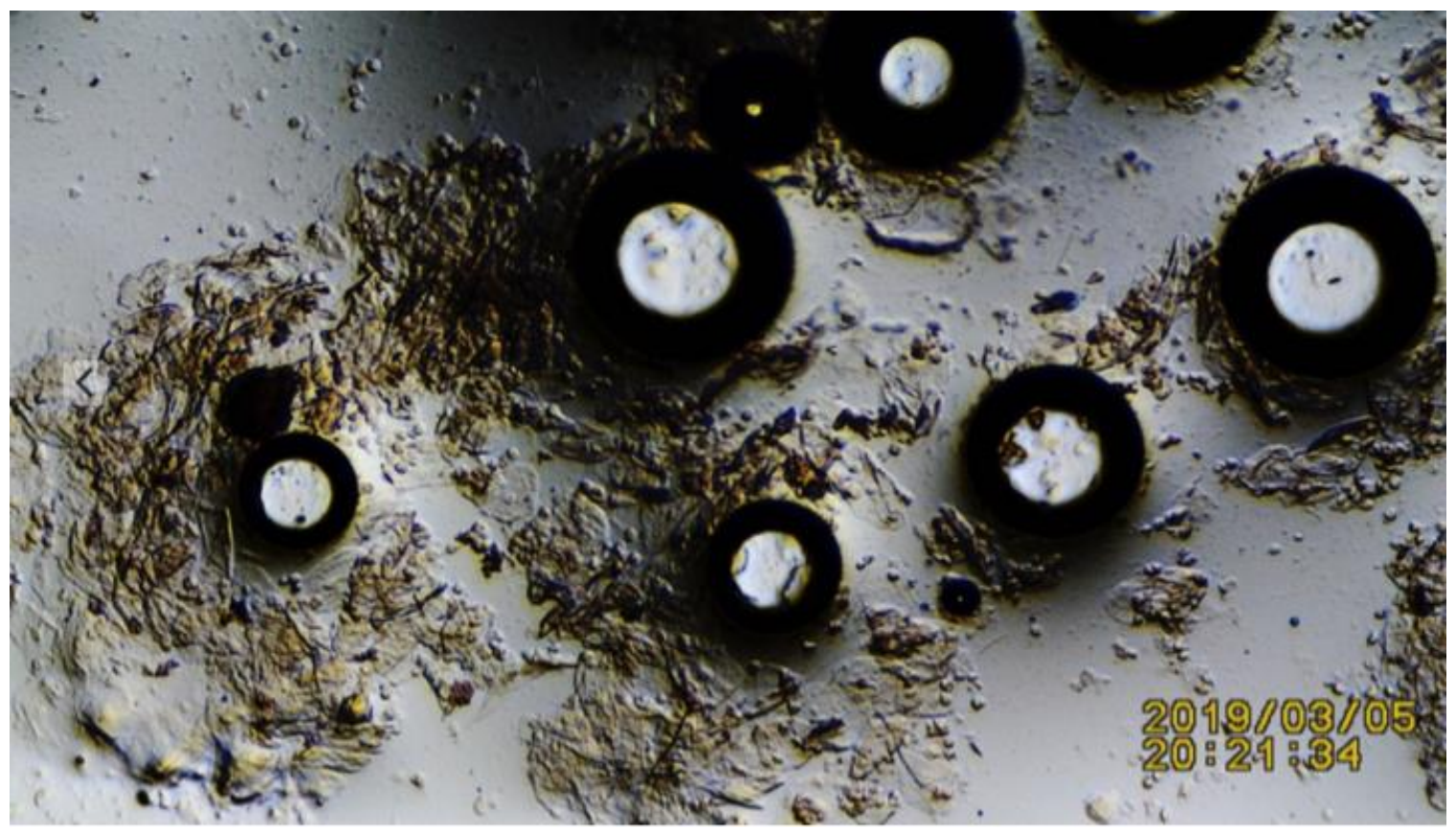

Figure 12: Oxygen bubbles nest paramagnetism attracting cells and debris placed on slide via swab + saliva reacting to powder catalase.

\section{Discussion}

\section{What is new in this manuscript?}

The introduction of a tabletop microscopy technique demonstrating the deleterious effect on both nucleated and non-nucleated cell deformations by the rupturing of oxygen bubbles and oxygen bubbles attraction.

The findings herein reported goes beyond the concept of In vitro to in vivo extrapolation; which refers to the qualitative or quantitative transposition of experimental results or observations made in vitro to predicts phenomena in vivo in biological organisms and described as to "misrepresent potential in vivo effects" (15). In this manuscript there is no extrapolation, cells are demonstrated undergoing actual changes in video recordings, this from exposure to exogenous material placed on TIBS preparations and rupture of oxygen bubbles.

\section{Prokaryotic Cells}

In non-nucleated cells, such RBCs, the paramagnetism of oxygen bubbles, as well as the rupture of the oxygen molecules caused cell deformation and observed changes in adhesion of RBC with WBCs. 
The development of two table top optical microscopy methodologies have allowed for the demonstration of magnetic fields as an additional factor in both prokaryotic and eukaryotic cells deformations.

\section{Eukaryotic Cells}

In the case of nucleated cells, shape and possible metabolic changes also due to magnetic attraction-repulsion, as well as rupture of oxygen bubbles.

The magnetic effect on prokaryotic RBCs documented an increase in WBC/RBC adhesion (Fig. 7) also the bubble bursting caused RBCs deformations (Figs.4,6). In Figure $5+$ video, the nonnucleated RBCs are also seen attracted by the paramagnetism of oxygen bubbles, cell deformations are also seen.

\section{Qualitative Graphical Demonstrations}

The magnetic effect and oxygen bubble rupture energy on eukaryotic cheek cells showed cells deformation including intercellular (nucleus) changes (Figs 8,9,10 + video recording). The magnetic effect and also energy released by ruptures oxygen bubbles also induced cell and possible metabolic changes in prokyorotic (RBCs) cells. (Figs 1 through $7+$ videos)

\section{Conclusions}

Of importance is the documentation of oxygen paramagnetic attraction and bubbles bursting as a factor in cells deformations, Why? Because is in support of a biophysics hypothesis in cancer origin, attributed to energy released from $\mathrm{H}_{2} \mathrm{O}_{2}$ breakdown induced paramagnetic oxygen molecules and possible micro bubbles during cell respiration. In this author's opinion, taking into consideration the data presented, and the fact that "bubbles are the bistable hydrophobic gates responsible for the on-off transitions of single channel currents" (15) adds credence to a Biophysics Cancer Origin Hypothesis. In addition, current development of bursting of micro bubbles (via ultrasound cavitation) for drug delivery could possibly interfere with cell signaling (16).

The questions arise

- Are intra or inter cellular membranes signaling disrupted by the bursting of micro bubbles during cell respiration?

- Could bursting of sonicated micro bubbles during proposed drug delivery to solid tumors contributing to further cancer genesis? (17).

- Answers: The data presented in this manuscript, as well as others is in support of a biophysical additional factor in cancerogenesis. ROS decomposition as primary, Shock waves by Oxygen bubbles near cells as secondary.

\section{Limitations}

It could be argued that the blood tissue studied was from one subject $n=1$, the author; therefore having little or no statistical relevancy.

Two instances mitigate the limitation:

1) In a prior published paper, blood drops tested on three other volunteers (one male and two females) showed similar RBCs deformations (13). 
2) Since all blood drops studies were from one person $n=1$ (the author), and $\mathrm{RBCs}$ deformations were seen, a precautionary medical evaluation was requested and done. A standard cell blood count including a pathologist review of the author's blood smear was done during a routine medical visit. The test was done February $12^{\text {th }} 2019$ at a reputable community hospital. Today is February $15^{\text {th }} 2019$. There was no mention of any abnormal dehydrated RBCs (Equinocytes) or deformed RBCs in the form of Dacrocytes (Teardrop). Those official findings mitigate the $\mathrm{n}=1$ limitation. $\mathrm{CBC}$ findings available upon request.

\section{List of Abbreviations}

Dacrocytes $=$ Deformed RBCs in the form of teardrops.

Diamagnetism $=$ When material repels opposing magnetic fields ie:RBCs.

EMFs $=$ Electromagnetic Fields

RBCs $=$ Red Blood Cells

Paramagnetism= Material attracting opposing magnetic fields. Ie: Iron particles, Oxygen.

ROS $=$ Reactive Oxygen Species

TIBS = Acronym for Temporary In Vivo Blood Smears due to in vitro blood smears preparation showing temporary in vivo characteristics and herein branded Temporary In Vivo Blood Smears (TBIS)

\section{Declaration Page}

Ethics approval and consent to participate:

The hair and blood samples were from the author's body.

Consent for publication:

I give consent to publish the manuscript.

Availability of data and material:

In my possession. Stored in my computer files- Available upon request.

Competing interests: None declared.

Funding: No external funding- Self funded by author.

Authors" contributions: main author, idealized concept, performed research, wrote and submitted manuscript.

\section{Acknowledgements}

None

\section{References}

[1] Embi A. A. (2016). Endogenous electromagnetic forces emissions during cell respiration as additional factor in cancer origin. Cancer cell international, 16, 60. doi:10.1186/s12935-016-0337y

[2] Jingzhu Wang, Akihisa Abe, Taketoshi Koita, Mingyu Sun, Yiwei Wang, and Chenguang Huang,. (2018) Study of sterilization effects on marine Vibrio sp. using interaction of cavitation with shock wave in a narrow water chamber. Journal of Applied Physics 124, 213301 (2018); https://doi.org/10.1063/1.5052521 
[3] Martin H Skjelvareid, Mette S W Breiland, Atle Mortensen (2018) Ultrasound as potential inhibitor of salmon louse infestation-A small-scale study Aquaculture Research, 49(8), 2684-2692 https://doi.org/10.1111/are.13729

[4] Williamson, S.J., Romani, G.-L., Kaufman, L., Modena, I. 1983 Biomagnetism An Interdisciplinary Approach. eBook. ISBN 978-1-4757-1785-3 Springer. DOI 10.1007/978-1-47571785-3 (Online) 9781475717877 (print)

[5] Pauling, L., \& Coryell, C. D. 1936. The Magnetic Properties and Structure of Hemoglobin, Oxyhemoglobin and Carbonmonoxyhemoglobin. Proceedings of the National Academy of Sciences of the United States of America, 22(4), 210-6

[6] Baule G.M, McFee R. 1963 Detection of the magnetic field of the heart. American Heart Journal ;66: 95-96 PBMID: 14045992.

[7] Cohen D. 1972 Magnetoencephalography: Detection of the Brain's electrical activity with a superconducting magnetometer. Science ;175: 664-666 PMID: 5009769.

[8] Corsini E, Acosta V, Baddour N, Higbe J, Lester B, Licht P, Patton B, Prouty M, Budker D. 2011 Search for plant biomagnetism with a sensitive atomic magnetometer. J Appl Physics.;109: 07470$1-5$.

[9] Hong, F.T. 1995. Magnetic field effects on biomolecules, cells, and living organisms. Bio Systems, $363,187-229$.

[10] Scherlag BJ, Huang B, Zhang L, Sahoo K, Towner R, Smith N, Embi AA, Po SS. 2015 Imaging the Electromagnetic Field of Plants (Vigna radiata) Using Iron Particles: Qualitative and quantitative correlates. Journal of nature and Science ; 1: e61.

[11] Embi AA. (2015) Jacobson JI, Sahoo K, Scherlag BJ Demonstration of Inherent Electromagnetic Energy Emanating from Isolated Human Hairs. Journal of Nature and Science 2015; 1: e55.

[12] Poole, G. (2018) Law of Universal Magnetism, F $=\mathrm{ke} \times$ H. Journal of High Energy Physics, Gravitation and Cosmology, 4, 471-484. doi: 10.4236/jhepgc.2018.43025.

[13] Embi AA. (2018). "BIOMAGNETISM AS FACTOR IN RED BLOOD CELLS DEFORMATION." International Journal of Research - Granthaalayah, 6, 46-57. https://doi.org/10.5281/zenodo.2528404

[14] M. Sepioni, R. R. Nair, I.-Ling Tsai, A. K. Geim and I. V. Grigorieva (2012) Revealing common artifacts due to ferromagnetic inclusions in highly oriented pyrolytic * EPL (Europhysics Letters), Volume 97, Number 4

[15] Shannon M. Bell Xiaoqing Chang, John F.Wambaugh, David G.Allena, Mike Bartelsc, Kim L.R. et al. (2017) In vitro to in vivo extrapolation for high throughput prioritization and decision making. https://doi.org/10.1016/j.tiv.2017.11.016

[16] Roth, R., Gillespie, D., Nonner, W., \& Eisenberg, R.E. (2008). Bubbles, gating, and anesthetics in ion channels. Biophysical journal, 94 11, 4282-98.

[17] Chen, H., \& Hwang, J.H. (2013). Ultrasound-targeted microbubble destruction for chemotherapeutic drug delivery to solid tumors. Journal of therapeutic ultrasound. $1 ; 1: 10$. doi: 10.1186/2050-5736-1-10.

\footnotetext{
*Corresponding author.

E-mail address: embi21@ att.net
} 